\title{
Novas referências de rodofíceas marinhas bentônicas para o litoral brasileiro
}

\author{
José Marcos de Castro Nunes ${ }^{1,2,4}$ \& Silvia Maria Pita de Beauclair Guimarães ${ }^{3}$ \\ ${ }^{1}$ Laboratório de Algas Marinhas - LAMAR, Departamento de Botânica, Instituto de Biologia, \\ Campus de Ondina, Universidade Federal da Bahia - UFBA, \\ CEP 40170-280, Salvador, BA, Brasil \\ ${ }^{2}$ Herbário HUNEB, Departamento de Ciências Exatas e da Terra, Campus II, \\ Universidade do Estado da Bahia - UNEB, \\ Alagoinhas, BA, Brazil, http://www.uneb.br \\ ${ }^{3}$ Instituto de Botânica, Seção de Ficologia, \\ Av. Miguel Estéfano, 3687, CEP 04301-902, São Paulo, SP, Brasil, http://www.ibot.sp.gov.br \\ ${ }^{4}$ Autor para correspondência: José Marcos de Castro Nunes, \\ e-mail:jmcnunes@ufba.br,http://www.ufba.br
}

NUNES, J.M.C \& GUIMARÃES, S.M.B. New references of rhodophytes from the Brazilian coast. Biota Neotrop., 8(4): http://www.biotaneotropica.org.br/v8n4/en/abstract?article+bn02008042008

Abstract: Seven taxa of benthic marine rodophytes are reported for the first time from the Brazil littoral: Acrochaetium corymbiferum (Thur. in Le Jolis) Batters, A. liagorae Børgesen, Aglaothamnion herveyi (M. Howe) Aponte, D.L. Ballant. \& J.N. Norris, Crouanophycus latiaxis (L.A. Abbott) Athanas., Grallatoria reptans M. Howe and Gelidiella sanctarum Feldmann \& Hamel. Gelidiopsis repens (Kütz.) Weber Bosse this is the new reference to the Atlantic Ocean. The material collected on mediolittoral and infralittoral was deposited in the Herbarium Alexandre Leal Costa (ALCB) at the Universidade Federal da Bahia. Reference to the original description, basionym, morphological description, geographical distribution and taxonomical comments are presented for each taxon studied.

Keywords: Rhodophyta, new records, Brazil, Atlantic Ocean.

NUNES, J.M.C \& GUIMARÃES, S.M.B. Novas referências de rodofíceas marinhas bentônicas para o litoral brasileiro. Biota Neotrop., 8(4): http://www.biotaneotropica.org.br/v8n4/pt/abstract?article+bn02008042008

Resumo: Sete táxons de rodofíceas marinhas bentônicas são referidos pela primeira vez para o litoral brasileiro: Acrochaetium corymbiferum (Thur. in Le Jolis) Batters, A. liagorae Børgesen, Aglaothamnion herveyi (M. Howe) Aponte, D.L. Ballant. \& J.N. Norris, Crouanophycus latiaxis (L.A. Abbott) Athanas., Grallatoria reptans M. Howe e Gelidiella sanctarum Feldmann \& Hamel. Gelidiopsis repens (Kütz.) Weber Bosse é pela primeira vez referido para o Oceano Atlântico. As coletas foram realizadas no medio e infralitoral. O material está depositado no Herbário Alexandre Leal Costa. Referência da descrição original, basiônimo, descrição morfológica, distribuição geográfica e comentários taxonômicos são apresentados para cada táxon estudado.

Palavras-chave: Rhodophyta, novos registros, Brasil, Oceano Atlântico. 


\section{Introdução}

O estado da Bahia possui o litoral mais extenso do Brasil com $1.103 \mathrm{~km}$ (Bahia-CDT 1999), tendo, como limite norte, a barra do Rio Real no município de Jandaíra, e, como limite sul, a barra do Riacho Doce no município de Mucuri. O litoral apresenta grande diversidade de ambientes litorâneos: praias arenosas, recifes de corais, formações de arenito, costões rochosos e manguezais.

Segundo a divisão fitogeográfica proposta por Horta et al. (2001), esse litoral faz parte da Região Tropical que se caracteriza pela presença de flora relativamente rica, estabelecida dominantemente sobre recifes de arenito, tendo seu limite norte o oeste do Ceará e como limite sul, o sul do estado da Bahia. A região se distingue por águas oligotróficas e abundância de substratos duros, propícios ao crescimento de macroalgas marinhas (Horta et al. 2001).

Oliveira Filho (1977) fez referência a 327 espécies de rodofíceas para o litoral brasileiro e Horta et al. (2001) referiram 388 táxons infragenéricos. Nos últimos anos houve um incremento significativo no número de espécies de rodofíceas referidas para o Brasil, atualmente estão representadas por 455 táxons infragenéricos, sendo que 57\% dos táxons referidos para o Brasil ocorrem no litoral baiano (Nunes 2005a). Esse grupo é o mais diversificado no litoral da Bahia, com 241 espécies, constituindo-se no terceiro maior número já registrado para a região brasileira.

No Brasil, devido a suas dimensões continentais, ainda se fazem necessários estudos de inventários florísticos em várias regiões, pois os dados são incompletos e fragmentados, existindo ainda, vários grupos taxonômicos a serem estudados, sobretudo na região Nordeste.

O primeiro levantamento sistemático de rodofíceas marinhas bentônicas realizado para o estado da Bahia foi publicado por Nunes (1997), ao estudar quatro famílias de rodofíceas em duas praias de Salvador. Desde então, outros artigos tratando das rodofíceas marinhas bentônicas do litoral baiano têm sido publicados (Nunes 1998, Lucio \& Nunes 2002, Figueiredo \& Steneck 2002, Barreto et al. 2004, Nunes 2005a, Nunes 2005b, Nunes 2007, Lyra et al. 2007, Nunes et al. 2008a, Nunes et al. 2008b). Porém existem trabalhos de cunho florístico de grande importância realizados no litoral baiano, dentre eles o de Joly et al. (1969), onde estudaram as algas de Abrolhos e propuseram a criação de um Parque Nacional Marinho.

A grande maioria das espécies de rodofíceas do litoral baiano apresenta uma distribuição ampla na região tropical americana e, em uma escala menor, na região tropical do Indo-Pacífico (Oliveira Filho 1977, Horta et al. 2001). Segundo Horta et al. (2001), a flora de macroalgas marinhas do litoral brasileiro, bem como a do Caribe, teve uma origem comum, ou seja, a partir do Indo-Pacífico.

Este trabalho tem como objetivo estudar e descrever sete novos registros de espécies de rodofíceas para o litoral brasileiro e integra o Projeto "Algas marinhas bentônicas do litoral da Bahia, Brasil" desenvolvido pela Universidade Federal da Bahia em parceria com a Universidade do Estado da Bahia.

\section{Material e Métodos}

O material estudado foi coletado no litoral baiano em diversas praias dos Municípios de Cairú (Morro de São Paulo - 13 23' 03.48' S e $38^{\circ} 54^{\prime} 26.10^{\prime \prime} \mathrm{W}$ ), Conde (Barra do Itariri - $11^{\circ} 58^{\prime} 57.28^{\prime \prime} \mathrm{S}$ e

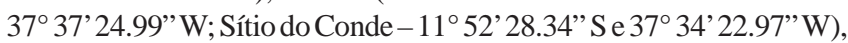
Entre Rios (Subaúma - $12^{\circ} 15^{\prime} 30.23^{\prime \prime} \mathrm{S}$ e $37^{\circ} 46^{\prime} 55.27^{\prime \prime} \mathrm{W}$ ), Ilhéus (Gravatá - $14^{\circ} 50^{\prime} 37.48^{\prime \prime} \mathrm{S}$ e $39^{\circ} 01^{\prime} 25.75^{\prime}$ ' W), Itacaré (Engenhoca - $14^{\circ} 18^{\prime} 33.50^{\prime}$ 'S e $38^{\circ} 59^{\prime} 18.54$ " W), Salvador (Itapoã - $12^{\circ} 57^{\prime} 04.34^{\prime \prime}$ S e $38^{\circ} 22^{\prime}$ 01.90” W; Stella Maris $12^{\circ} 56^{\prime} 28.46^{\prime \prime}$ S e $38^{\circ} 19^{\prime} 51.68^{\prime \prime}$ W), Santa Cruz de Cabrália (Arakakaí - $16^{\circ} 17^{\prime} 02.13$ " S e $39^{\circ} 01$ ' 18.63” W), Uruçuca (Serra Grande - $14^{\circ} 19^{\prime} 04.50^{\prime \prime}$ S e $38^{\circ} 59^{\prime} 29.74^{\prime \prime}$ W) e Vera Cruz (Penha
- 12 ${ }^{\circ} 59^{\prime} 07.93^{\prime}$ ' S e $38^{\circ} 37^{\prime} 07.89^{\prime}$ 'W). As localidades estão especificadas no material examinado de cada espécie estudada.

Para a disposição dos táxons em ordens e famílias seguiu-se Wynne (2005). Os dados de distribuição geográfica foram obtidos em Guiry \& Guiry (2008).

As coletas foram feitas no mediolitoral com auxílio de espátula, e no infralitoral através de mergulho em apinéia até $5 \mathrm{~m}$, equipamento SCUBA ou draga tipo Holme, detalhe sobre a coleta de cada táxon está especificado após listagem do material examinado. Todo o material coletado foi fixado em formalina a $4 \%$, diluída em água do mar e as preparações foram coradas com solução aquosa de azul de anilina a $0,5 \%$, acidificada com HCL $1 \mathrm{~N}$. Para a observação do número de núcleos das células utilizou-se a técnica adotada por Wittmann (1965), modificada por Fujii (1998). Pequenas porções dos exemplares previamente fixados em formol foram lavadas em água e distendidas em lâmina cuidadosamente, sobre as quais foram adicionadas algumas gotas de Carnoy (etanol acético, 3:1). Após 5 minutos, retirou-se o Carnoy e gotejou-se o corante de Wittman. A seguir, colocou-se a lamínula e em seguida a lâmina foi aquecida rapidamente em uma chama fraca para acelerar a reação do corante com o material nuclear. Após a verificação dos núcleos, a solução corante foi substituída gradativamente por glucose de milho (Karo) $50 \%$.

Para cada estrutura notável, foi mencionado os valores extremos, máximo e mínimo, medidos através de régua milimetrada (estruturas maiores) e ocular micrométrica inserida no microscópio óptico (Zeiss).

Os estudos foram feitos em microscópio estereomicroscópio e óptico, marca Zeiss ${ }^{\circledR}$, observando-se a morfologia externa e interna das estruturas vegetativas e de reprodução. Fotomicrografias das estruturas foram feitas em microscópio de captura de imagem Zeiss e as ilustrações na câmara-clara em microscópio da mesma marca.

O material identificado encontra-se depositado no Herbário Alexandre Leal Costa (ALCB) do Departamento de Botânica do Instituto de Biologia da Universidade Federal da Bahia e Herbário da Universidade de São Paulo (SPF).

\section{Resultados e Discussão}

\section{ACROCHAETIALES, ACROCHAETIACEAE}

Acrochaetium corymbiferum (Thur. in Le Jolis) Batters. J. Bot. 40 (suppl.): 59. 1902

1. Chantransia corymbiferum (Thur. in Le Jolis). Mém. Soc. Sci. Nat. Chebourg 10: 197. 1893. (Figuras 1-6).

Talo endofítico com 2-3 mm de altura, com 13-18 $\mu \mathrm{m}$ de diâmetro, produzindo um filamento ramificado com 8-14 $\mu \mathrm{m}$ de diâmetro que penetra profundamente no talo do hospedeiro. Eixos eretos, originados do esporo basal persistente, com ramificação alterna a irregular, abundante na porção superior. Células dos filamentos eretos cilíndricas, com 8-12 $\mu \mathrm{m}$ de diâmetro e 27-48 $\mu \mathrm{m}$ de comprimento. Monosporângios terminais produzidos unilateralmente na porção adaxial dos ramos laterais, simples, ovóide, com 10-21 $\mu \mathrm{m}$ de diâmetro e 11-31 $\mu \mathrm{m}$ de comprimento, séssil ou com pedicelo de célula única, ocasionalmente associado com os gametângios. Gametófitos dióicos. Espermatângios pedicelados com uma ou duas células, laterais ou em pequenos ramos, formando um agrupamento de aspecto corimboso, espermácios de 4-6 $\mu \mathrm{m}$ de diâmetro. Carposporófitos ovóides com 8-13 $\mu \mathrm{m}$ de diâmetro e 13-19 $\mu \mathrm{m}$ de comprimento, laterais nos eixos principais, com pedicelo de uma a duas células e aspecto corimboso.

Material examinado: BRASIL, BAHIA, Cairú, Morro de São Paulo, Garapuá, 11.XI.2000, J.M. de C. Nunes, (ALCB 57804); 

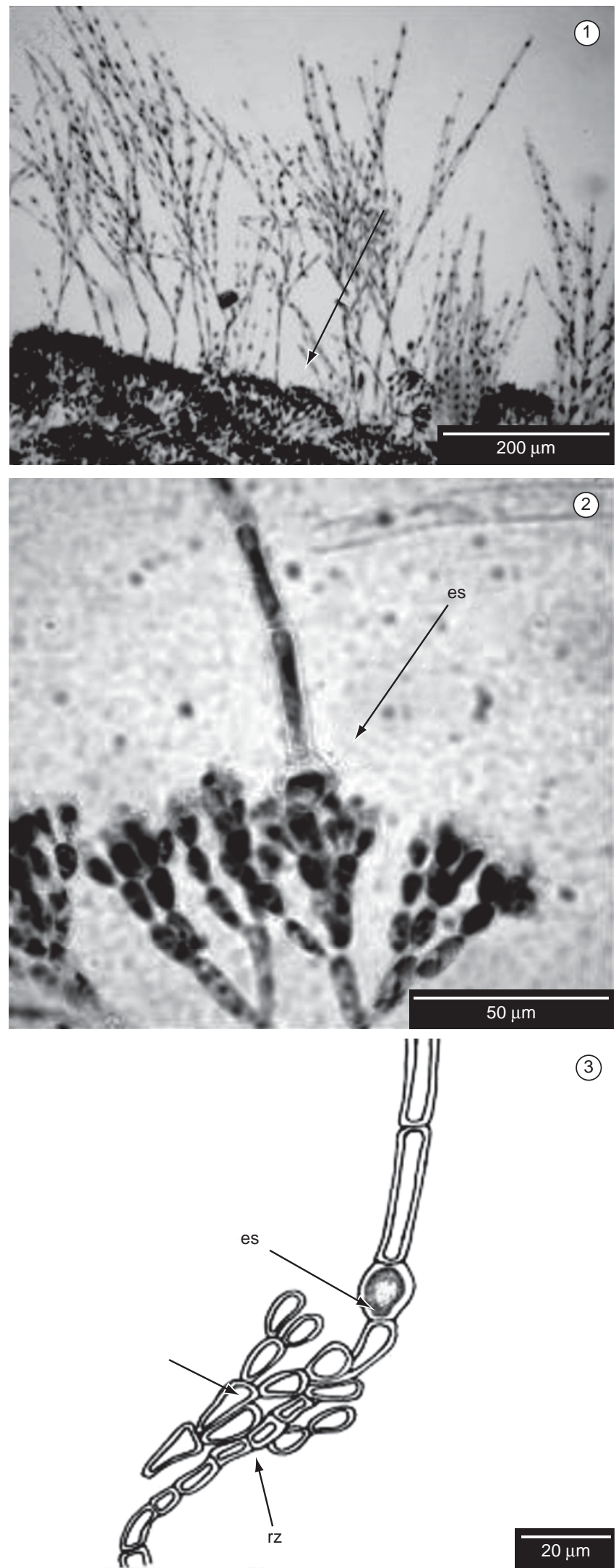

(3)

$20 \mu \mathrm{m}$
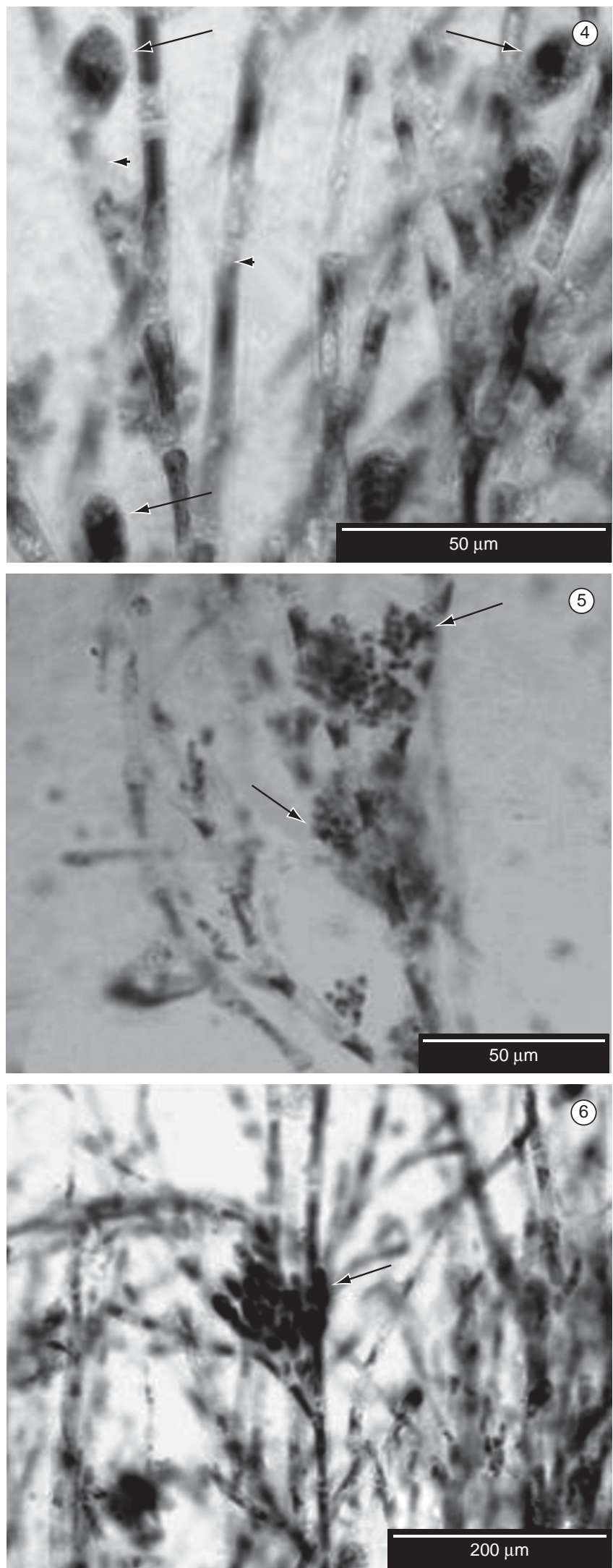

Figuras 1-6. Acrochaetium corymbiferum: 1) aspecto geral do talo crescendo sobre Liagora valida (seta); 2) esporo persistente na região basal (es); 3) ilustração do esporo persistente na região basal do filamento (es) com rizóide (rz) penetrando na alga hospedeira (seta); 4) detalhe dos filamentos (cabeça de seta) com monosporângios (setas); 5) filamentos com espermatângios (setas); e 6) filamento com grupo de carposporângios (seta) organizados em forma corimbosa.

Figures 1-6. Acrochaetium corymbiferum: 1) plant over Liagora valida (arrow); 2) persistent spore in the basal region of the filament; 3) spore in basal region (es) with rhizoids (rz) penetrating into the host algae (arrow); 4) detail of the filaments (arrow head) with monosporangia (arrow); 5) filaments with spermatangia (arrow); and 6) filaments with carposporangia group (arrow) in corymbose shape. 
Salvador, Ilha dos Frades, Paramana, J.M. de C. Nunes, S.M.P.B. Guimarães \& M.T. Fujii, 06.XI.2002, (ALCB 57805); Itapoã, J.M. de C. Nunes, 15.VII.1992, (ALCB 57806).

Exemplares coletados no mediolitoral, em ambiente recifal e no infralitoral a $5 \mathrm{~m}$ de profundidade. Crescendo sobre Liagora valida Harv.

Schneider (1983), Schneider \& Searles (1991) e Abbott (1999) mencionam este táxon crescendo sobre várias espécies do gênero Liagora. Os exemplares estudados e identificados como Acrochaetium corymbiferum concordam com as descrições dos autores mencionados anteriormente, diferenciando-se das outras espécies referidas para o Brasil, por apresentar eixos eretos originados do esporo basal persistente, um filamento ramificado que penetra profundamente no talo do hospedeiro, monosporângios terminais produzidos unilateralmente na porção adaxial dos ramos laterais e disposição dos espermatângios, bem como dos carposporófitos com aspecto corimboso.

Distribuição geográfica: Oceano Atlântico (Irlanda, França, Grã-Bretanha, U.S.A. e Caribe - Bermudas), Mar Mediterrâneo (Itália, Espanha e Egito) e Oceano Pacífico (Havaí). Primeira referência para o Atlântico Sul.

2. Acrochaetium liagorae Børgesen. Dansk Bot. Ark. 3: 58. 1915. (Figuras 7-8).

Talo endofítico, filamentos unisseriados, prostrados, compostos por número variado de células. Células com forma triangular, medindo 7-15 $\mu \mathrm{m}$ de diâmetro e 20-28 $\mu \mathrm{m}$ de comprimento. Filamentos eretos ausentes. Pêlos longos e incolores, medindo 5-6 $\mu \mathrm{m}$ de diâmetro e 200-300 $\mu \mathrm{m}$ de comprimento, crescendo a partir do vértice das células triangulares dos filamentos rastejantes. Monosporângios sésseis ou pedicelados, simples ou em pares, irregularmente arranjados, medindo 11-14 $\mu \mathrm{m}$ de diâmetro e 18-22 $\mu \mathrm{m}$ de comprimento. Espermatângios subesféricos, 3-4 $\mu \mathrm{m}$ de diâmetro. Não foram observados exemplares femininos.

Material examinado: BRASIL, BAHIA, Cairú, Morro de São Paulo, Garapuá, J.M. de C. Nunes, 11.XI.2000, (ALCB 57804); Salvador, Ilha dos Frades, Paramana, J.M. de C. Nunes, S.M.P.B. Guimarães \& M.T. Fujii, 06.XI.2002, (ALCB 57805); Itapoã, J.M. de C. Nunes, 15.VIII.1992, (ALCB 57806).

Exemplares coletados no mediolitoral, em região recifal e no infralitoral a $5 \mathrm{~m}$ de profundidade e $24 \mathrm{~m}$ (draga Holme). Crescendo sobre Liagora valida. Affonso-Carrillo et al. (2003) comentam que, em relação ao hábito, Acrochaetium liagorae
Børgesen é semelhante à Liagorophyla endophytica Yamada; ambas as espécies são relativamente comuns como endófitas de algas "liagoróides" nas Ilhas Canárias. A. liagorae, contudo, apresenta células vegetativas pequenas, monosporângios diferenciados, espermatângios formando grupos e divisão transversal do carpogônio fertilizado (Woelkerling 1971). No material estudado foi possível observar a maioria dessas características, exceto o plano de divisão do carpogônio, devido a ausência de exemplares femininos no material estudado.

Os exemplares estudados distinguem-se das espécies de Acrochaetium referidas para o Brasil por apresentar células do filamento de forma triangular, pêlos longos crescendo no vértice das células triangulares, ausência de filamentos eretos e monosporângios diferenciados. Essas características corroboram a identificação deste táxon como A. liagorae, concordando com as descrições e ilustrações de Børgesen (1915), Abbott (1999) e Affonso-Carrillo et al. (2003).

Distribuição geográfica: Oceano Atlântico (Ilhas Canárias e Madeira e Caribe - Barbados), Oceano Pacífico (Havaí e Austrália) e Oceano Índico (Tazânia, Vietnan e Filipinas). Primeira referência para o Atlântico sul.

\section{CERAMIALES, CERAMIACEAE}

Aglaothamnion herveyi (M. Howe) Aponte, D.L. Ballant. \& J.N. Norris. Phycologia 33: 232. 1994.

1. Callithamnion herveyi M. Howe. Flora of Bermuda: 528. 1918. (Figuras 9-14).

Talo filamentoso unisseriado, aspecto arborescente, vermelhoesverdeado, iridescente, com até $6 \mathrm{~cm}$ de altura, fixo ao substrato por apressório discóide formado por filamentos rizoidais simples ou ramificados. Eixo usualmente percurrente em exemplares jovens, mas geralmente indistintos em exemplares mais velhos. Ramificação principal radial e râmulos dispostos alternadamente. Eixo principal medindo de $150-350 \mu \mathrm{m}$ de diâmetro próximo à

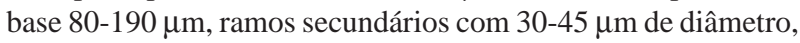
voltados para o eixo principal, conferindo ao talo um aspecto corimboso. Células dos eixos e ramos uninucleadas. Eixo fortemente corticado por filamentos rizoidais que se originam na base dos ramos laterais, corticação atenuando-se em direção ao ápice. Filamentos rizoidais originando ramos adventícios descendentes, com 13-18 $\mu \mathrm{m}$ de diâmetro. Tetrasporângios sés-
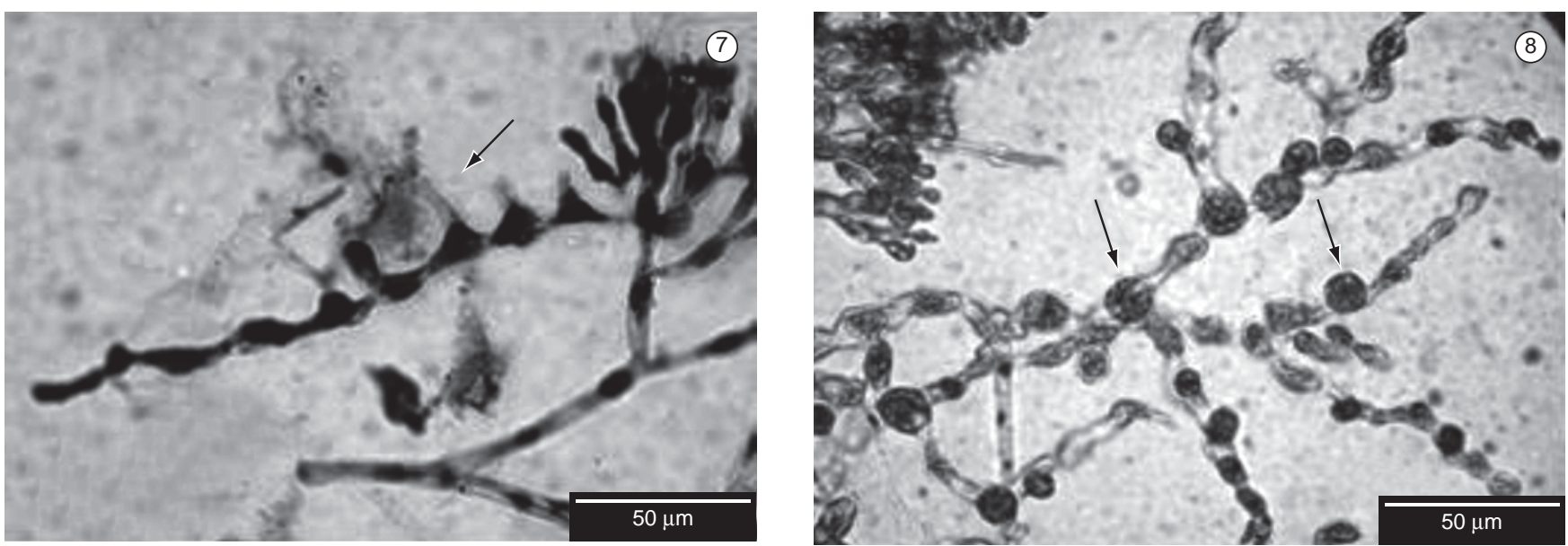

Figuras 7-8. Acrochaetium liagorae: 7) filamentos prostrados com pêlos (seta); e 8) filamentos com monosporângios (setas).

Figures 7-8. Acrochaetium liagorae: 7) decumbent filaments with hairs (arrow); and 8) filaments with monosporangia (arrows). 
Rodofíceas do litoral brasileiro
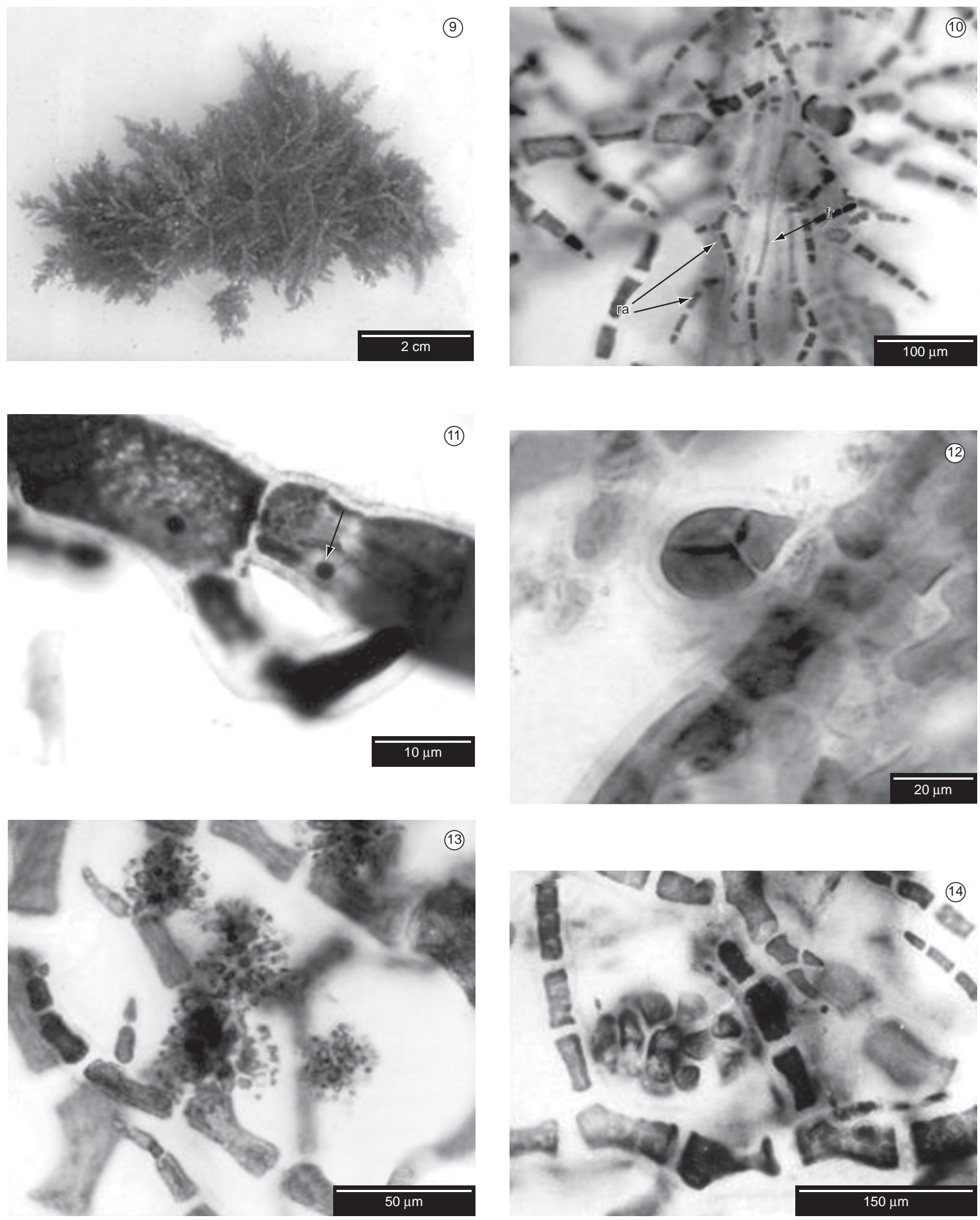

Figuras 9-14. Aglaothamnion herveyi: 9) aspecto geral; 10) detalhe da porção basal com corticação, mostrando filamento rizoidal (fr) e ramo adventício descendente (ra); 11) célula vegetativa uninucleada (seta); 12) râmulo com tetrasporângio séssil; 13) detalhe dos ramos terminais férteis com espermatângios; e 14) ramo fértil com gonimolobo.

Figuras 9-14. Aglaothamnion herveyi: 9) habit; 10) detail of the basal portion with cortication, showing rhizoidal filament (fr) and descending adventitious branch (ra); 11) uninucleate cell (arrow); 12) branch with sessil tetrasporangia; 13) detail of the terminal branch with spermatangia; and 14) branch with gonimolobe. 
seis, tetraedricamente divididos, solitários, com 30-40 $\mu \mathrm{m}$ de diâmetro e 45-53 $\mu \mathrm{m}$ de comprimento. Gametófitos dióicos. Ramos espermatangiais ramificados várias vezes, espermatângios agrupados sobre um pedicelo, formados adaxialmente na porção subapical das células dos ramos de última ordem, um por célula; espermatângios com 2-3 $\mu \mathrm{m}$ de diâmetro. Ramo carpogonial com quatro células, dispostas em "U” quando maduro. Carposporófito com quatro gonimolobos, dois grandes e dois pequenos, esféricos com 100-220 $\mu \mathrm{m}$ de diâmetro.

Material examinado: BRASIL, BAHIA, Conde, Barra do Itariri, J.M. de C. Nunes, 05.VII.1997, (ALCB 57680, 60642); Sítio do Conde, J.M de C. Nunes., 04.VIII.1997, (ALCB 57660); Entre Rios, Subaúma, J.M de C. Nunes \& A. Minervino Netto, 05.V.2000, (ALCB 65113); Ilhéus, Gravatá, J.M de C. Nunes \& A. Minervino Netto, 25.VIII.2000, (ALCB 57616, 57643, 57663, 57762, 60909); J.M de C. Nunes e col., 09.II.2001, (ALCB 57659, 57737, 60912, 60913); Itacaré, Engenhoca, J.M de C. Nunes. \& A. Minervino Netto, 23.VIII.2000, (ALCB 57664); Salvador, Stella Maris, J.M de C. Nunes, 09.VII.2002, (ALCB 60881); Santa Cruz de Cabrália, Arakakaí, J.M de C. Nunes \& G.M. Lyra, 09.III.2001, (ALCB 57642, 57661); Uruçuca, Serra Grande, J.M de C. Nunes, 08.X.95, (ALCB 60986); Vera Cruz, Penha, J.M de C. Nunes \& S.M.P.B. Guimarães, 05.XI.2002, (ALCB 57644).

Exemplares coletados no mediolitoral, epilítica e epífita em formações recifais e costões rochosos. Crescem sobre Centroceras clavulatum (C. Agardh in Kunth) Mont. in Durieu de Maisonneuve, Corallina panizzoi Schnetter, Gelidiella acerosa (Forssk.) Feldman \& Hamel, Gelidiopsis variabilis Grev. Ex J. Agardh) F. Schmitz, Halimeda discoidea Decne., Haliptilon subulatum (J. Ellis \& Sol.) H.W. Johans., Haloplegma duperreyi Mont., Heterosiphonia gibbesii Aregood, Jania adhaerens J.V. Lamour. e Laurencia arbuscula Sond.. Esses exemplares estão associados a Anadyomene stellata (Wulfen in Jacq.) C. Agardh e Wrangelia argus (Mont.) Mont.

O gênero Aglaothamnion Feldm.-Maz., foi descrito para acomodar as espécies uninucleadas de Callithamnion Lyngb. As características nucleares e reprodutivas que definiram Aglaothamnion foram consideradas inconsistentes por alguns autores, sendo motivo de controvérsia a respeito de sua validade como gênero. Alguns deles como Dixon \& Price (1981) e Womersley (1998) não reconhecem o gênero Aglaothamnion, considerando que a forma do ramo carpogonial não está associada com a condição uni ou multinucleada das células vegetativas. L'Hardy-Halos \& Rueness (1990), L'Hardy-Halos \& Maggs (1991), Aponte et al. (1994) e Aponte et al. (1997) concluíram que somente a característica nuclear é suficientemente válida para separar esses dois gêneros. Neste trabalho, seguiu-se estes últimos autores reconhecendo os dois gêneros, ou seja, células de Aglaothamnion uninucleadas e de Callithamnion plurinucleadas.

Aglaothamnion herveyi se distingue facilmente de Aglaothamnion boergesenii (Aponte \& D.L. Balantine) L'Hardy-Halos \& Rueness. e de A. cordatum (Børgesen) Feldm.-Maz devido à presença de corticação nos eixos principais (Aponte et al. 1994). Aglaothamnion felipponei (M. Howe) Aponte, D.L. Ballantine \& J.N. Norris e A. herveyi são espécies que se confundem (Aponte et al. 1997). Ambas foram descritas por Howe, a primeira para o Uruguai (Howe \& Taylor, 1931) e a segunda para as Bermudas (Howe 1918). A. felliponei foi referida (como Callithamnion felipponei M. Howe) para a região sul e sudeste do Brasil (Joly 1957, 1965, Oliveira Filho 1969, Cordeiro-Marino 1978, Yoneshigue 1985).

As principais diferenças entre Aglaothamnion herveyi e A. felipponei, segundo Aponte et al. (1994), estão no padrão de ramificação dos ramos principais e últimos ramos laterais. Em A. herveyi, a ramificação dos últimos ramos é mais consistentemente dística quando comparada com a ramificação de A. felipponei. Adicionalmente, A. herveyi apresenta filamentos rizoidais originando ramos adventícios descendentes, como observado nos espécimes estudados. Porém, em A. feliponei esses ramos estão ausentes. Ambas as espécies possuem pedicelos sustentando os ramos espermatangiais, um caráter único entre os representantes da tribo Callithamnieae.

Ramificação principal radial, ramos secundários voltados para o eixo principal, com râmulos dispostos alternadamente conferindo ao talo um aspecto corimboso e filamentos rizoidais originando ramos adventícios descendentes, são características que aproximam nossos exemplares de $A$. herveyi descrito para o Caribe por Aponte et al. (1997).

Distribuição geográfica: Oceano Atlântico (Caribe - Cuba, Colômbia, Bermuda e Flórida). Primeira referência para o Atlântico sul.

Crouanophycus latiaxis (I.A. Abbott) Athanas. Nova Hedwigia 67: 517. 1998.

\section{Antithamnionella latiaxis I.A. Abbott. Phycologia 18: 220. 1979.} (Figuras 15-23).

Talo filamentoso, com até $1 \mathrm{~cm}$ de altura, composto por eixo ereto e prostrado, fixo ao substrato por rizóides basais digitados, originados de células axiais e células basais dos ramos verticilados; eixo ereto com 20-40 $\mu \mathrm{m}$ de diâmetro, ecorticado, de cada célula axial originam-se três ramos verticilados, subdicotomicamente ramificados, voltados para os eixos de crescimento indeterminado, formação de novos eixos independentemente, como um quarto ramo lateral no verticilo de três râmulos; células glandulares ausentes, tetrasporângios esféricos a oblongados, tetraedricamente divididos, sésseis, inseridos adaxialmente nas células basais dos ramos, com 28-47 $\mu \mathrm{m}$ de diâmetro e 35-65 $\mu \mathrm{m}$ de comprimento. Estruturas espermatangiais localizados nas células apicais dos ramos, compostas por uma única célula suportando verticilos de 1-4 células mãe do espermatângio, cada uma produzindo 1-3 espermácios. Carposporófitos originados nas porções apicais dos eixos axiais, com dois gonimolobos, um grande, com 40-60 x 50-80 $\mu \mathrm{m}$ e outro um pouco menor, com $30-40 \times 35-60 \mu \mathrm{m}$.

Material examinado: BRASIL, BAHIA, Vera Cruz, Penha, J.M. de C. Nunes, S.M.P.B. Guimarães \& M.T. Fujii, 05.XI.2002, (ALCB 57637).

Exemplares coletados no mediolitoral, em ambiente recifal. Crescendo sobre Amphiroa fragilissima. Foram coletados exemplares tetraspóricos, femininos e masculinos.

O gênero Crouaniella Athanas. foi criado para acomodar duas espécies tropicais das costas da América Central e regiões vizinhas: Crouaniella latiaxis (I.A. Abbott) Athanas. na costa atlântica e C. mcnabii (E.Y. Dawson) Athanas. na costa pacífica. Contudo, o gênero Crouaniella é um antigo homônimo do nome de um fungo, Crouaniella (P.A. Saccardo) Lambote. Por essa razão, Athanasiadis (1998) propôs o "nomen novum" denominado Crouanophycus.

Crouanophycus caracteriza-se por apresentar: número consistente de três ramos verticilados por célula axial; desenvolvimento de rizóides das células axiais do eixo; formação de novos eixos como um quarto ramo lateral no verticilo de três râmulos; a divisão subdicotômica dos eixos verticilados e a produção de tetrasporângios nas células basais dos ramos sem afetar a ramificação. Tetrasporângios esféricos (em Crouanophycus mcnabbi) 

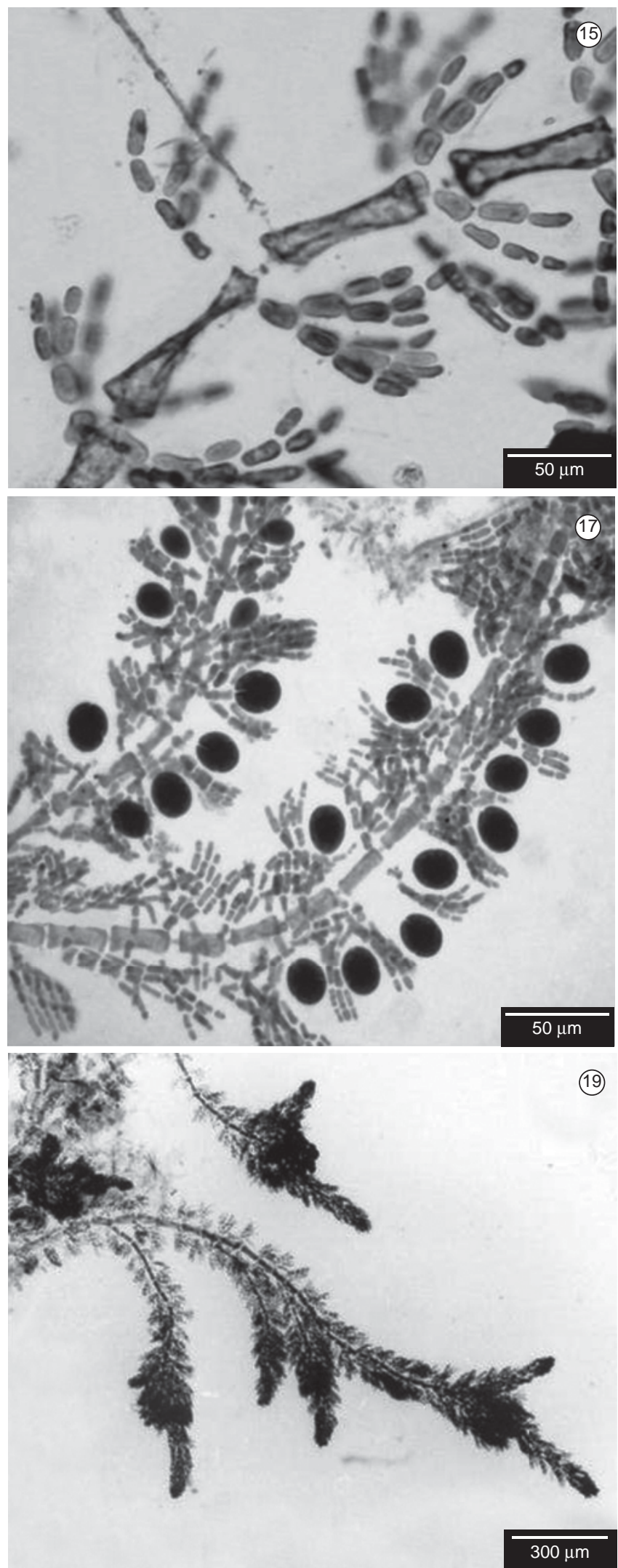
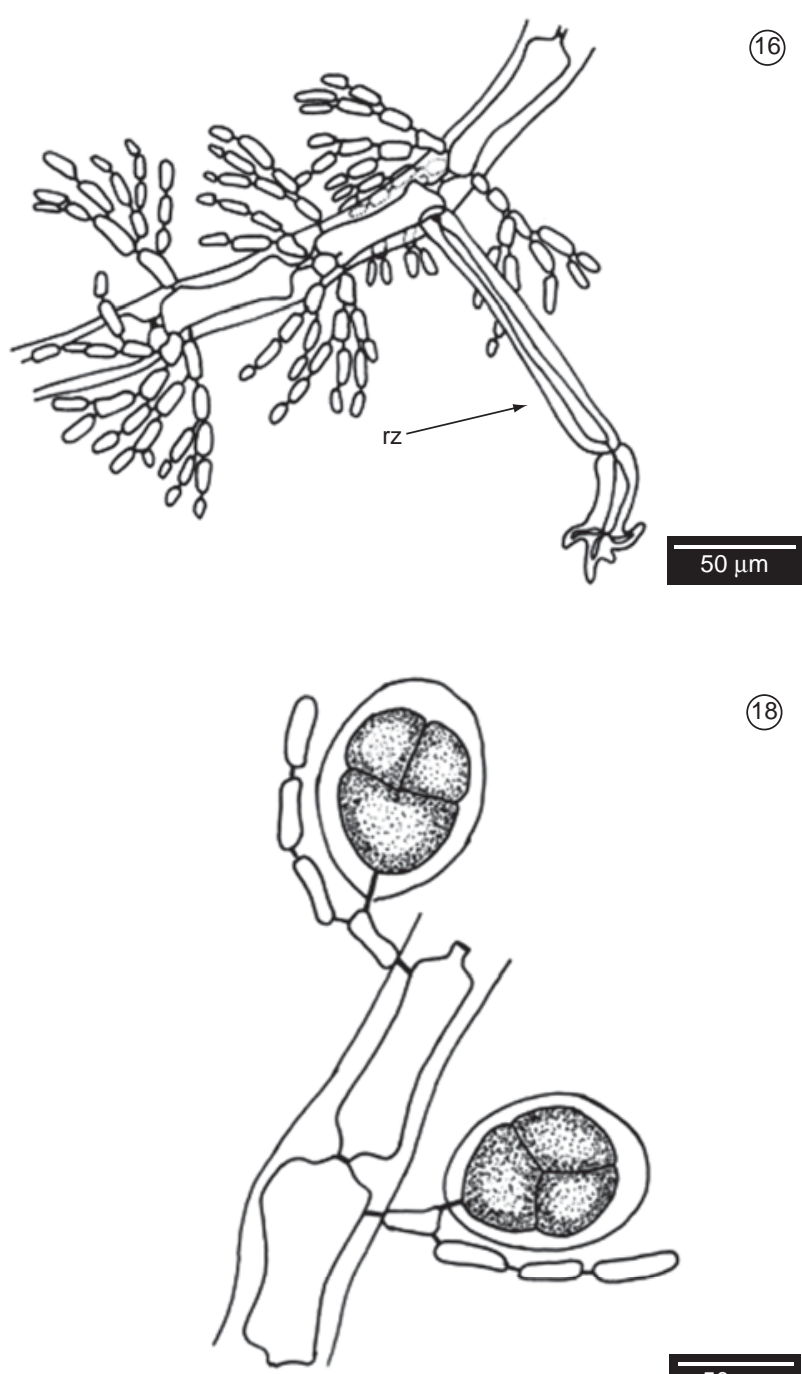

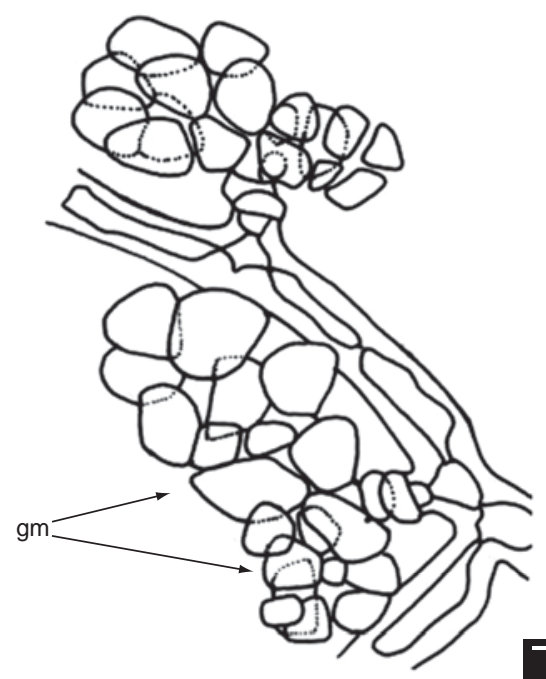

(20)

Figuras 15-20. Crouanophycus latiaxis: 15) detalhe da ramificação verticilada no talo; 16) ramificação do talo e origem do rizóide (rz); 17) tetrasporófito com tetrasporângios originados nas células periaxiais sem afetar o padrão de ramificação; 18) tetrasporângios originados nas células periaxiais dos ramos verticilados; 19) aspecto geral do exemplar feminino; e 20) carposporófito com dois gonimolobos (gm).

Figures 15-20. Crouanophycus latiaxis: 15) detail of the whorl-branchs in the axial cells ramification; 16) ramification and rhizoid (rz); 17) tetrasporophyte with tetrasporangia borne on periaxial cells without affecting the branch ramification; 18) oblongates tetrasporangia borne on periaxial cells of the whorl branch; and 19) habit of the female plant; and 20) carposporophyte with two gonimolobos (gm). 

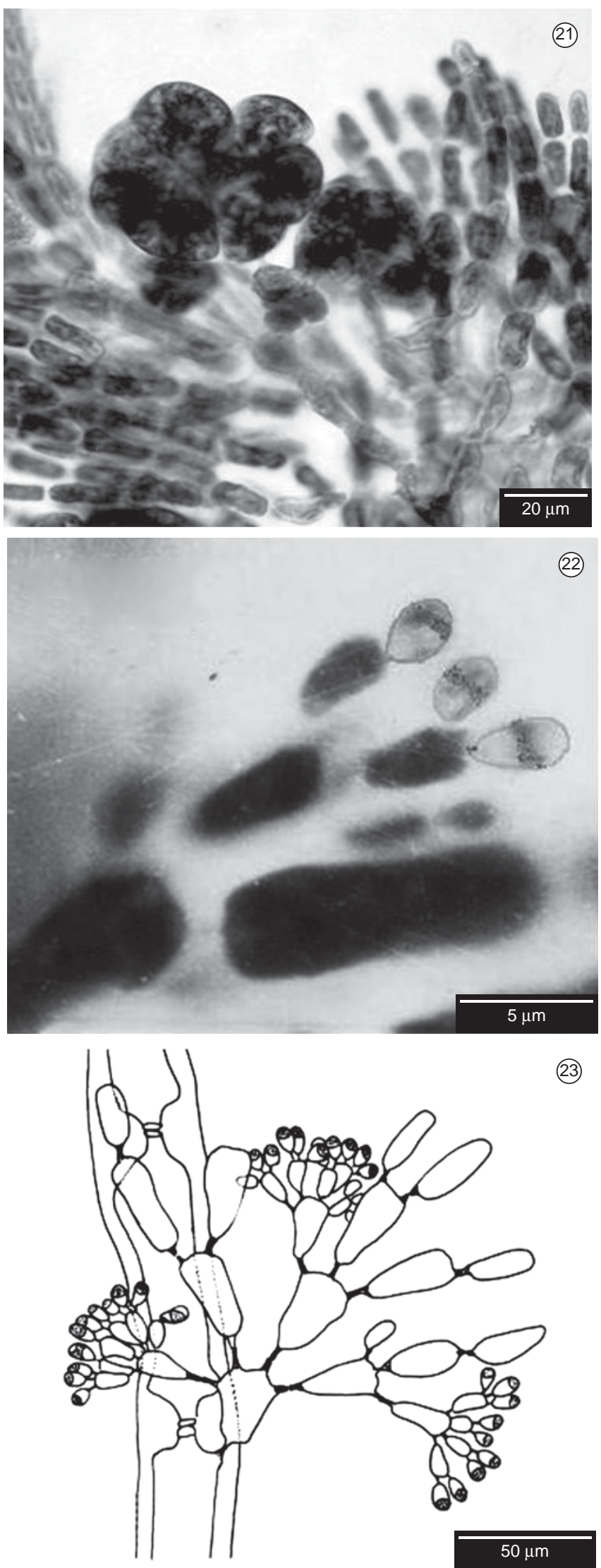

Figuras 21-23. Crouanophycus latiaxis: 21) detalhe do gonimolobo; 22) detalhe do ramo espermatangial; e 23) arranjo do ramo espermatangial.

Figures 21-23. Crouanophycus latiaxis: 21) detail of the gonimolobe; 22) spermatangial branch; and 23) disposition of the spermatangial branch. são típicos de Crouanieae, contudo tetrasporângios oblongados (em C. latiaxis) ocorrem na maioria dos membros de Dohrnielleae. Células glandulares ausentes, como na maioria dos gêneros "crouanióides", aparentemente devido a uma redução dessas células glandulares. Abbott (1979) também reportou (mas não ilustrou) tetrasporângios "ocasionalmente pedunculados e células glandulares inconspícuas, usualmente adaxiais, localizadas nas células basais das pínulas, ocasionalmente com uma segunda célula glandular nas células distais adjacentes". Nenhuma dessas características foram observadas nos espécimes tipo examinados por Abbott (1979). Detalhes da pós-fertilização e desenvolvimento do carposporófito são desconhecidos. Contudo, Abbott (1979) reportou cistocarpos terminais na coleção tipo.

Athanasiadis (1996) realizou estudos de filogenia com exemplares da família Ceramiaceae e verificou que Antithamnionella e Crouanophycus separam-se em clados distantes um do outro, reforçando a hipótese de que se trata de gêneros distintos, confirmado pelas peculiaridades morfológicas externas desses dois gêneros.

As espécies de Antithamnionella apresentam em comum as seguintes características: eixos eretos originados lateralmente a partir de eixos prostrados; ramos laterais substituindo um ramo verticilado, inconsistência em número de râmulos por verticilos e presença de células ganglionares sésseis. Características essas que claramente diferencia de Crouanophycus.

Os exemplares baianos foram identificados como Crouanophycus latiaxis por apresentar: três ramos verticilados por célula axial, podendo originar um quarto ramo que dará origem a um novo eixo; desenvolvimento de rizóides das células axiais do eixo; divisão subdicotômica dos eixos verticilados e a produção de tetrasporângios oblongados originados nas células basais dos ramos sem afetar a ramificação, localizados nas células proximais dos ramos, estruturas espermatangiais compostas por uma única célula suportando verticilos de 1-4 células mãe do espermatângio, cada uma produzindo 1-3 espermácios, além da ausência de células glandulares, concordando com as descrições de Abbott (1979), Bucher \& Norris (1995) e Athanasiadis (1996) e diferenciando das espécies de Antithamnionella (A. atlantica, A. boergesenii e A. breviramosa) referidas para o litoral brasileiro.

Crouanophycus latiaxis foi coletada no infralitoral superior, 3-12 m, sobre Codium e Dictyota, incluindo gametófitos femininos, estruturas espermatangiais dos talos masculinos foram encontradas nas células apicais dos ramos e foram mencionados como sendo compostas por uma única célula suportando verticilos de 1-4 (6) células mãe do espermatângio, cada uma produzindo (1) 2 (3) espermácios. Embora estes padrões não sejam claramente ilustrados, os mesmos são diferentes do que é conhecido nas espécies de Antithamnionella. Esses talos férteis ocorreram na Martinica, Lesser Antilhes e foram descritos por Bucher \& Norris (1995) como Antithamnionella. Estas características coincidem com os exemplares baianos.

Distribuição geográfica: Oceano Atlântico (Caribe - Porto Rico). Primeira referência para o Atlântico sul.

3. Grallatoria reptans M. Howe. The Bahama flora: 560. 1920. (Figuras 24-26).

Talo filamentoso, unisseriado, organização dorsiventral, com até $1 \mathrm{~cm}$ de altura, composto de eixo prostrado de crescimento indeterminado, de onde partem ramos eretos de crescimento determinado. Eixos prostrados com 50-65 $\mu \mathrm{m}$ de diâmetro e ramificação oposta; ramos eretos de crescimento determinado com 20-35 $\mu \mathrm{m}$ de diâmetro, ramificados de modo alternado ou verticilado abaixo e pseudodicotômico acima, com 4-8 células 


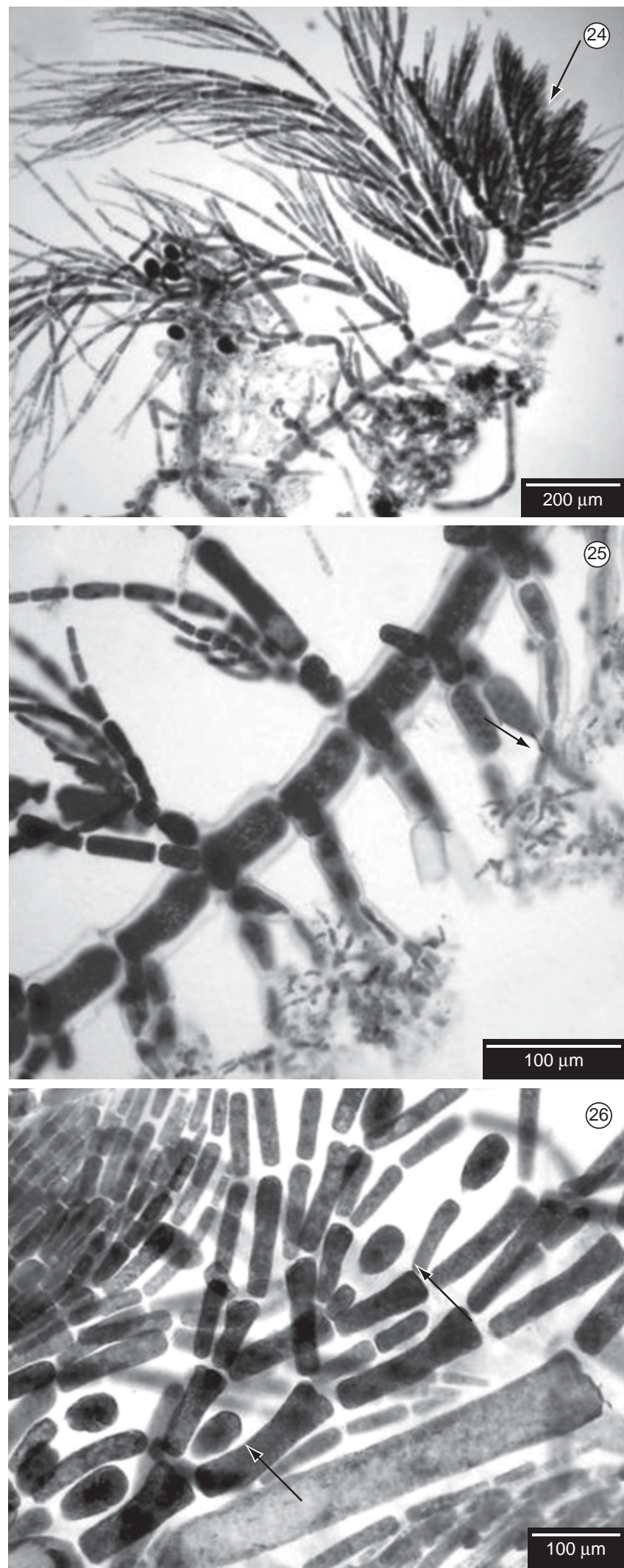

Figuras 24-26. Grallatoria reptans: 24) aspecto geral mostrando o eixo rastejante com rizóides e ápice do ramo de crescimento indeterminado (seta); 25) rizóides multicelulares com extremidades digitadas (seta); e 26) ramos verticilados com tetrasporângios (setas).

Figuras 24-26. Grallatoria reptans: 24) habit of creeping axis with rhizoids and indeterminate branch (arrow); 25) multicellular rhizoids with digitate extremity (arrows); and 26) whorl branch bearing tetrasporangia (arrows). axiais em comprimento. Dois rizóides pluricelulares são originados por segmento nas células axiais dos eixos prostrados, com 15-20 $\mu \mathrm{m}$ de diâmetro e extremidades digitadas. Tetrasporângios tetraédricos, pedicelados, distribuídos alternadamente, com 25-47 $\mu \mathrm{m}$ de diâmetro.

Material examinado: BRASIL, BAHIA, Vera Cruz, Penha, J.M. de C. Nunes, S.M.P.B. Guimarães \& M.T. Fujii, 05.XI.2002, (ALCB 57614, 57615).

Exemplares coletados no mediolitoral, em ambiente recifal. Crescendo sobre coralinácea incrustante e Amphiroa anastomosans Weber Bosse.

Howe (1920) descreveu o gênero Grallatoria, baseado em G. reptans, porém, não incluiu ilustração do novo táxon. Como consequiência, o gênero foi pobremente entendido (Abbott, 1976) e devido a esse fato, alguns exemplares foram incluídos em um gênero semelhante, Callithamniella Feldm.-Maz.

Feldmann-Mazoyer (1938) descreveu o gênero Callithamniella baseado em duas espécies. Abbott (1976) transferiu C. tingitana (Schousb. ex Bornet) Feldm.-Maz. e C. flexilis Baardseth, para o gênero Grallatoria. Contudo, com base nos padrões de ramificação de G. reptans, Schneider (1984) e Yoneshigue (1985) consideraram Callithamniella como um gênero distinto. Wynne $\&$ Ballantine (1985) e Yoneshigue (1985) segregaram estes dois gêneros com base nos seguintes caracteres: padrão de divisão do tetrasporângio (cruciado em Callithamniella; tetraédrico em Grallatoria); padrão de ramificação dos eixos determinados (alterno em Callithamniella; sucessivamente oposto e verticilado em Grallatoria); rizóides (unicelulares em Callithamniella; pluricelulares em Grallatoria); número de rizóides por segmento (um em Callithamniella e dois em Grallatoria). Atualmente somente uma espécie de Grallatoria é reconhecida, G. reptans.

Grallatoria reptans era conhecida somente na sua localidade tipo (Bahamas), até que Abbott (1976) a reportou para as Ilhas Virgens. Mais tarde, Wynne \& Ballantine (1985) coletaram exemplares em Porto Rico, Stegenga \& Vroman (1987) em Curaçao, Sansón (1994) nas Ilhas Canárias e Schneider \& Searles (1997) nas Bermudas.

Os espécimes estudados foram identificados como Grallatoria reptans por apresentarem ramos determinados com 4-8 células axiais em comprimento, rizóides multicelulares e digitados, cada segmento originando dois rizóides e tetrasporângios tetraedricamente divididos. Sendo o gênero monoespecífico, as características da espécie são as do próprio gênero. Somente duas espécies de Callithamniella são referidas para o Brasil: Callithamniella tingitana (Schousboe) Feldmann-Mazoyer por Joly (1965) para o litoral norte de São Paulo e $C$. flexibilis Baardseth por Yoneshigue (1985) na áera de ressurgência de Cabo Frio, estado do Rio de Janeiro.

Distribuição geográfica: Oceano Atlântico (Ilhas Canárias e Caribe - Bahamas). Primeira referência para o Atlântico sul.

\section{GELIDIALES, GELIDIACEAE}

1. Gelidiella sanctarum Feldmann \& Hamel. Rev. Gén. Bot. 46:539. 1934. (Figuras 27-30).

Talo crescendo em densos tufos, cor escura, quase negra, 2 a $4 \mathrm{~cm}$ de altura, com porção estolonífera de onde partem eixos eretos cilíndricos a comprimidos, medindo 200-300 $\mu \mathrm{m}$ de diâmetro; célula apical saliente. Ramificação alterna a irregular, eixos pouco ramificados na porção inferior e abundantemente ramificados acima. Râmulos com ápice agudo. Porção estolonífera cilíndrica, não muito evidente, com 120-220 $\mu \mathrm{m}$ de diâmetro, fixa ao substrato por rizóides unicelulares de comprimento variado, com 4-5 $\mu \mathrm{m}$ de diâmetro. Em corte transversal da região mediana 

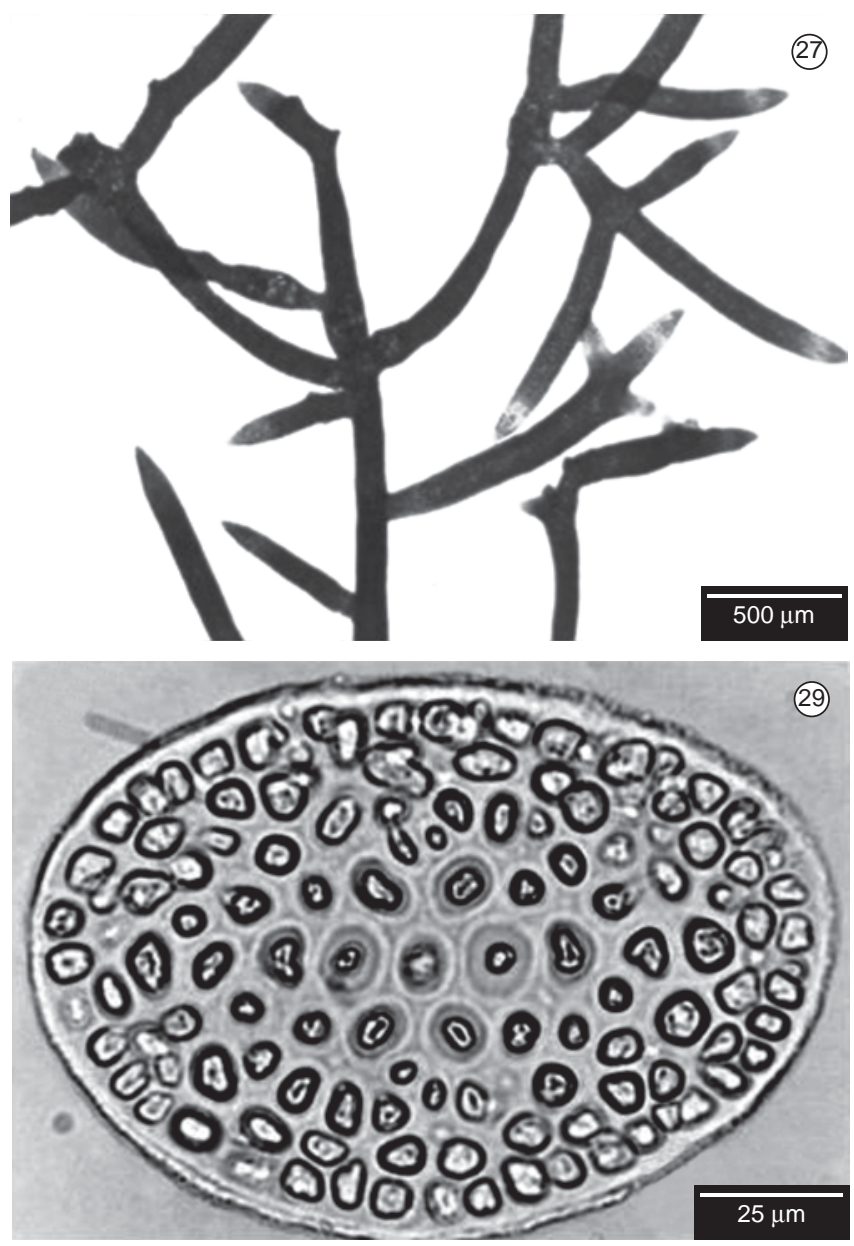
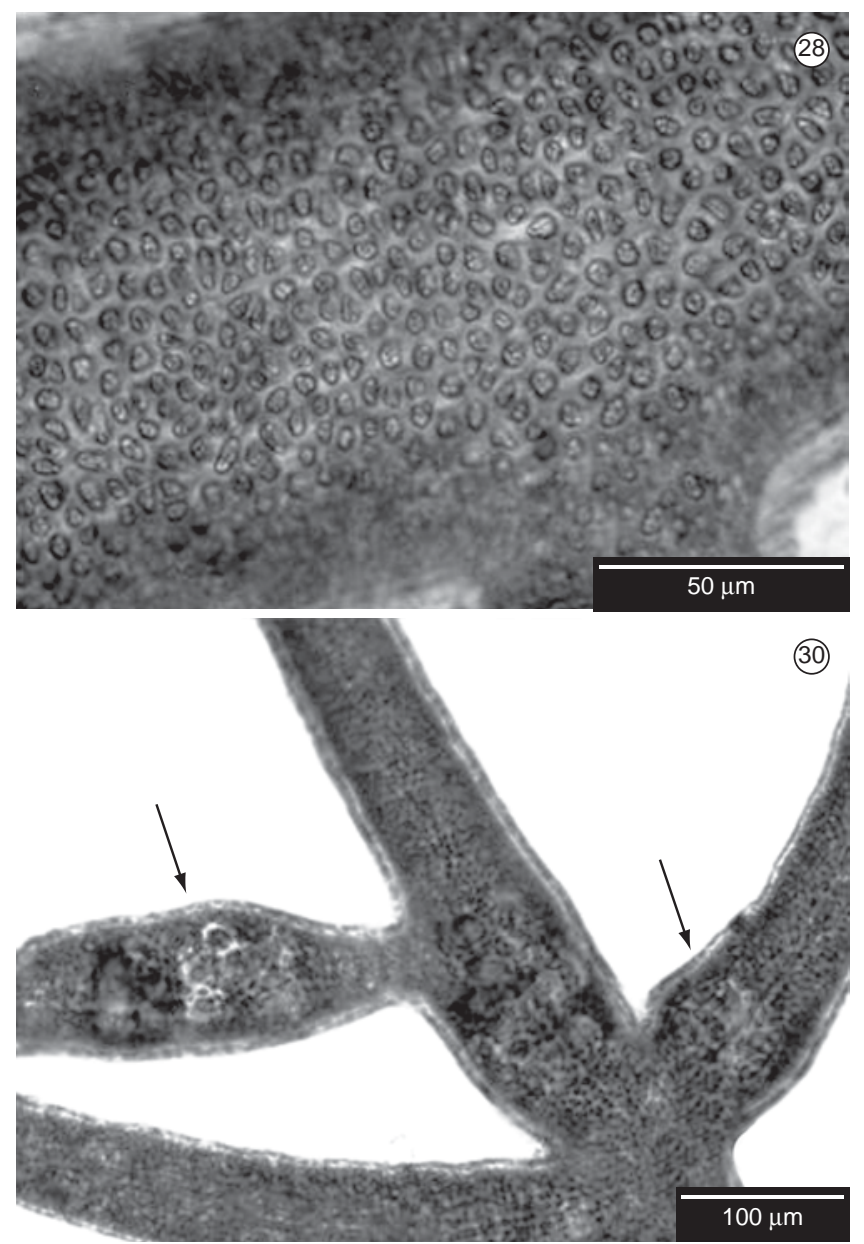

Figuras 27-30. Gelidiella sanctarum: 27) aspecto geral; 28) vista superficial das células corticais; 29) corte transversal do talo na região mediana; e 30) vista superficial do ramo com estiquídios tetrasporangiais intercalares (setas).

Figures 27-30. Gelidiella sanctarum: 27) habit; 28) superficial view of the cortical cells; 29) cross section of thallus in the median region; and 30) superficial view of the branch with intercalary stichidia tetrasporangia (arrow).

do talo, região cortical com 2 camadas de células pequenas, de formato irregular; em vista superficial, células dispostas irregularmente, medindo 2-5 x 4-5 $\mu \mathrm{m}$. Em corte transversal da região mediana do talo, região medular com 4-6 camadas de células grandes, arredondadas, de paredes espessas, com 10-14 $\mu \mathrm{m}$ de diâmetro, formando fileira de células na região central do talo. Tetrasporângios esféricos e irregularmente divididos, com 28-37 $\mu \mathrm{m}$ de diâmetro, distribuídos em fileiras paralelas regulares, longos estiquídios, cilíndricos, simples ou ramificados, ovalados, intercalares nos eixos principais e terminais em ramos jovens, com 170-420 x 800-1500 $\mu \mathrm{m}$. Não foram observados exemplares masculinos nem femininos.

Material examinado: BRASIL, BAHIA, Conde, Barra do Itariri, J.M. de C. Nunes, 05.VII.1997, (ALCB 65174). Rio Grande do Norte, Natal, Praia do Meio (546'45.60" S e 35 $11^{\circ}$ '34.67” W), Y. Ugadim, 20.XII.1989, (SPF 9021).

Para o litoral brasileiro são referidas atualmente 5 espécies de Gelidiella: G. acerosa (Forssk.) Feldmann \& Hamel, G. hancockii E.Y. Dawson, G. ligulata E.Y. Dawson, G. taylorii A.B. Joly e G. trinitatensis W.R. Taylor. Santelices (2004) segregou algumas espécies do gênero Gelidiella para o recém criado gênero Paviphycus, dentre elas, G. pannosa Feldmann \& Hamel (citadas para o Brasil), considerando-a como sinônimo de $P$. tenuissimus
(Feldman \& Hamel) Santel. [G.tenuissima]. Recentemente Afonso-Carrillo et al. (2007) transferiram uma outra espécie, (também citada para o Brasil) G. setaceae para P. setaceus (Feldmann) Afonso-Carrillo, Sanson, Sangil \& Diaz-Villa.

Os exemplares estudados foram identificados concordando com as descrições de Gelidiella sanctarum reportadas na literatura (Feldmann \& Hamel, 1934, Taylor 1960, Maggs \& Guiry 1987, Guiry \& Womersley 1992, Ganzon-Fortes 1994, Kraft \& Abbott 1998). Das espécies citadas para o Brasil, G. trinitatensis é a que mais se assemelha a $G$. sanctarum, porém difere dessa por apresentar região medular com 5-7 camadas de células, tetrasporângios tetraédricos distribuídos em fileiras paralelas em forma de "V", estiquídios terminais nos eixos principais ou ramos laterais.

Distribuição geográfica: Oceano Atlântico (Marrocos e Caribe) e Oceano Índico (Ilhas Seychelles). Primeira referência para o Atlântico sul.

\section{RHODYMENIALES, LOMENTARIACEAE}

1. Gelidiopsis repens (Kütz.) Weber Bosse. Siboga Exped. Monogr. 59: 425-426. 1928. 

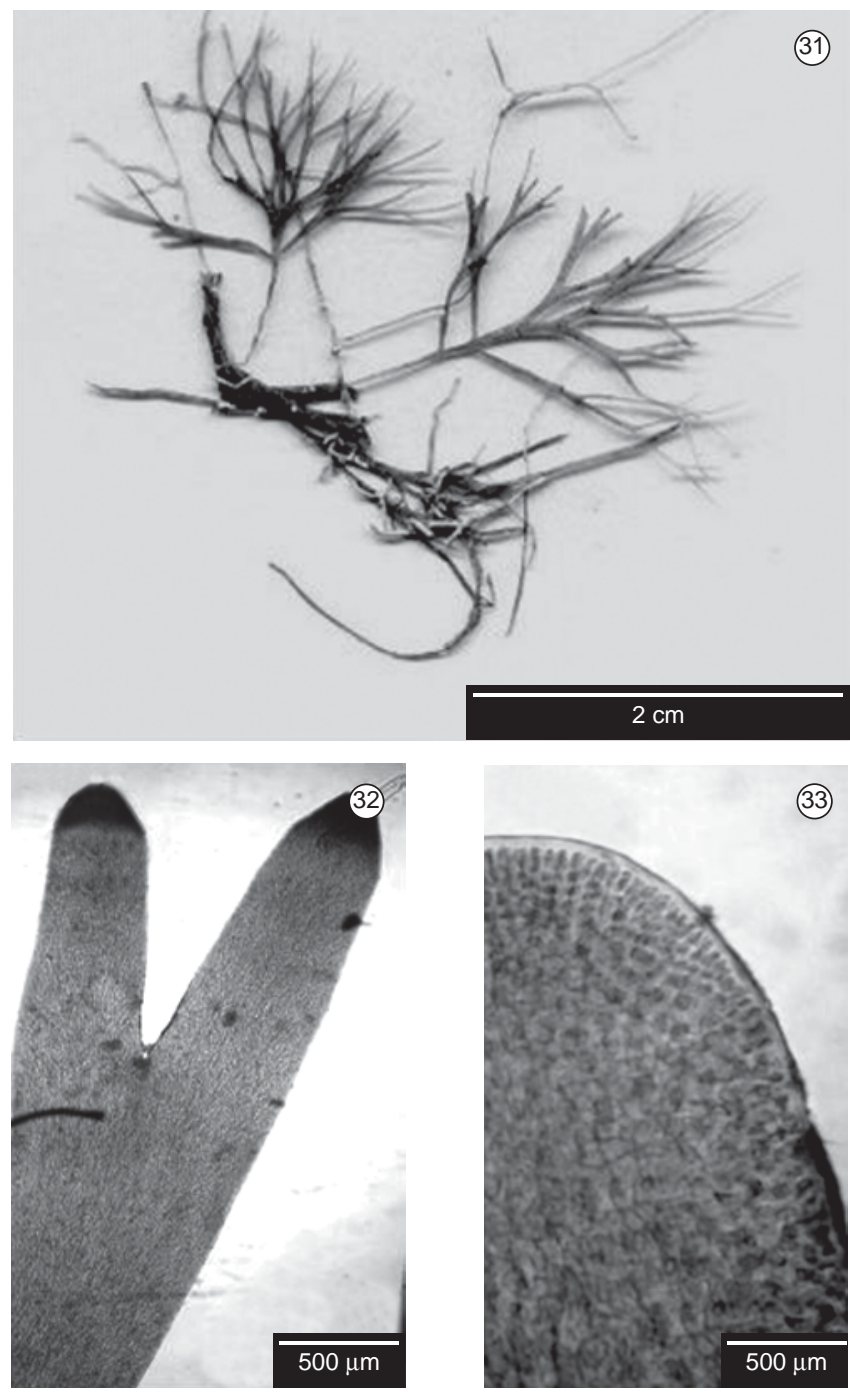

Figuras 31-33. Gelidiopsis repens: 31) aspecto geral; 32) região apical do talo; e 33) vista superficial da região apical mostrando o crescimento por margem de células.

Figures 31-33. Gelidiopsis repens: 31) habit; 32) detail of the apex region of thallus; and 33) superficial view of the apex region showing zone of meristematic cell.

Gelidium repens Kütz. Tab. Phyc. 18: 21. 1868. (Figura 31-33).

Talo em densos tufos, consistência firme, com até $5 \mathrm{~cm}$ de altura, vermelho. Fixa-se ao substrato por um sistema rizomatoso cilíndrico, de onde partem ramos eretos achatados, palmados e profundamente divididos; medindo $130-180 \mu \mathrm{m}$ de espessura e 500-650 $\mu \mathrm{m}$ de largura. Em corte transversal, região cortical com 2-3 camadas pigmentadas; região medular com várias camadas de células maiores, também pigmentadas. Não foram coletados exemplares férteis.

Material examinado: BRASIL, BAHIA, Cairú, Morro de São Paulo, S.M.P.B. Guimarães, 24.X.1995, (ALCB 57755).

Os exemplares estudados diferenciam-se de Gelidiopsis planicaulis (W.R. Taylor) W.R. Taylor e G. variabilis (Grev. Ex J. Agardh) F. Schmitz, espécies referidas para o Brasil, pela presença de um sistema rizomatoso cilíndrico originando ramos eretos achatados, palmados e profundamente divididos.
B $\varnothing$ rgesen (1952) identificou este táxon pela primeira vez como Gelidiopsis scoparia (Mont. \& Millardet) F. Schmitz para as Ilhas Maurício, mais tarde transferiu o táxon para G. acrocarpa (Harv.) F. Schmitz. Norris (1987) considerou G. acrocarpa como sinônimo taxonômico de G. repens (Wynne 1995).

Distribuição geográfica: Oceano Pacífico (Japão, Taiwan, Vietnam, Filipinas, Fiji, Samoa e Polinésia Francesa) e Oceano Índico (Indonésia, Índia, Sri Lanka, Tanzânia, Ilhas Seychelles, Ilhas Maurícios, Austrália e Nova Zelândia). Primeira referência para o Atlântico.

\section{Agradecimentos}

Ao PICDT - CAPES pela concessão da bolsa de Pós-Graduação ao primeiro autor. Aos anônimos revisores pela valiosa e criteriosa revisão do manuscrito.

\section{Referências Bibliográficas}

ABBOTT, I.A. 1976. On the red algal genera Grallatoria Howe and Callithamnionella Feldmann-Mazoyer (Ceramiales). Brit. Phycol. J. 11(2):143-149.

ABBOTT, I.A. 1979. Some tropical species related to Antithamnion (Rhodophyta, Ceramiaceae). Phycologia 18(3):213-227.

ABBOTT, I.A. 1999. Marine red algae of the Hawaiian Islands. Bishop Museum Press, Honolulu.

AFONSO-CARRILLO, J., SANSÓN, M. \& SANGIL, C. 2003. Colaconema ophioglossum comb. nov. and Liagorophila endophytica, two acrochaetioid algae (Rhodophyta) from eastern Atlantic. Cryptog. Algol. 24(2):107-116.

AFONSO-CARRILLO, J., SANSÓN, M., SANGIL, C. \& DIAZ-VILLA, T. 2007. New records of benthic marine algae from the Canary Islands (eastern Atlantic Ocean):morphology, taxonomy and distribution. Bot. Mar. 50(2):119-127.

APONTE, N.E., BALLANTINE, D.L. \& NORRIS, J.N. 1994. Culture studies on the morphology and life history Aglaothamnion herveyi (M. Howe) comb. nov., with notes on A. felliponei (M. Howe) comb. nov. (Ceramiaceae, Rhodophyta). Phycologia 33(2):231-238.

APONTE, N.E., BALLANTINE, D.L. \& NORRIS, J.N. 1997. Aglaothamnion halliae comb. nov. and A. collinsii sp. nov. (Ceramiales, Rhodophyta): resolution of nomenclatural and taxonomic confusion. J. Phycol. 33(3):81-87.

ATHANASIADIS, A. 1996. Morphology and classification of the Ceramioideae (Rhodophyta) based on phylogenetic principles. Opera Bot. 128:1-216.

ATHANASIADIS, A. 1998. Crouanophycus Athanasiadis, nom. nov. [三 Crouaniella 1996, nom. illeg.], a new genus of the Crouanieae (Ceramiales, Rhodophyta). Nova Hedwigia 67(3-4):517-518.

BAHIA - C.D.T. 1999. Programa de desenvolvimento turístico da Bahia oportunidades de investimento. Governo do Estado, Salvador.

BARRETO, M.B.B., BRASILEIRO, P.S., NUNES, J.M.C. \& AMADO FILHO, G.M. 2004. Algas marinhas bentônicas do sub-litoral das formações recifais da Baía de Todos os Santos, BA - 1. Novas Ocorrências. Hoehnea 31(3):321-330.

BØRGESEN, F. 1915. The marine algae of the Danish West Indies 3. Dansk Bot. Ark. 3(1):1-80.

BØRGESEN, F. 1952. Some marine algae from Mauritius. Additions to the parts previously published. IV. Biol. Meddel. Kongel. Danske Vidensk. Selsk. 18(19):72.

BUCHER, K.E. \& NORRIS, J.N. 1995. Marine algae to the Lesser Antilhes, including Mazoyerella kraftii sp. nov. (Ceramiales, Rhodophyta). Caribbean J. Sci. 31:1-24.

CORDEIRO-MARINO, M. 1978. Rodofíceas bentônicas marinhas do Estado de Santa Catarina. Rickia 7 (supl.):1-243. 
DIXON, P.S. \& PRICE, J.H. 1981. The genus Callithamnion (Rhodophyta:Ceramiaceae) in the British Isles. Bull. Brit. Mus. (Nat. Hist) Bot. 9(2):99-141.

FELDMANN, J. \& HAMEL, G. 1934. Observations sur qualques Gelidiacées. Rev. Gén. Bot. 46:528-550.

FELDMANN-MAZOYER, G. 1938. Un nouveau genre de Céramiacée:Callithamniella. Bull. des travaux publiés para la Stat. d’Aquiculture et de Pêchs de Castiglione. Ann. 91-102.

FIGUEIREDO, M.A. \& STENECK, R.S. 2002. Floristic and ecological studies of crustose coralline algae on Brazil's Abrolhos reefs. In Procceedings of the 9th International Coral Reef Symposium, Bali, p. 493-498.

FUJII, M.T. 1998. Estudos morfológicos, quimiotaxonômicos e citogenéticos em quatro espécies selecionadas de Laurencia (Ceramiales, Rhodophyta) do litoral brasileiro. Dissertação de Mestrado, Universidade Estadual Paulista, Rio Claro, 176 p.

GUIRY, M.D. \& GUIRY, G.M. 2007. AlgaeBase version 4.2. World-wide eletronic publication. http://www.algaebase.com. (último acesso em 10 julho 2007).

GUIRY, M.D. \& WOMERSLEY, H.B.S. 1992. Gelidiella minima sp. nov. (Rhodophyta) from Victoria, Australia: implications for the generic classification of the Gelidiaceae. Brit. Phycol. J. 27(1):165-176.

GANZON-FORTES, E.T. 1994. Gelidiella. In: Akatsuca, I. (ed.). Biology of Economic algae. SPB Academic Publishing, Netherlands.

HORTA, P.A., AMANCIO, E., COIMBRA, C.S. \& OLIVEIRA, E.C. 2001. Considerações sobre a distribuição e origem da flora de macroalgas marinhas brasileiras. Hoehnea 28(3):243-265.

HOWE, M.A. 1918. On some fossil and recent Lithothamniae of the Panama Canal Zone. US Nat. Mus. Bull. 1(1): 1-13.

HOWE, M.A. 1920. Algae. In Britton, N.L. \& Millspaugin, C.F. The Bahama Flora. Publ. by the Authors, p. 553-618.

HOWE, M.A. \& TAYLOR, W.R. 1931. Notes on some new or little-know marine algal from Brazil. Brittonia 1(1):7-33.

JOLY, A.B. 1957. Contribuição ao conhecimento da flora ficológica marinha da Baía de Santos e arredores. Bol. Bot. Univ. São Paulo 14 (305):196 + XIX pr.

JOLY, A.B. 1965. Flora marinha do litoral norte do Estado de São Paulo e regiões circunvizinhas. Bol. Bot. Univ. São Paulo 21(294):393.

JOLY, A.B., OLIVEIRA FILHO, E.C., \& NARCHI, W. 1969. Projeto de criação de um Parque Nacional Marinho na Região de Abrolhos, Bahia. Anais Acad. Brasil. Ci. (supl.) 41:247-251.

KRAFT, G.T. \& ABBOTT, I.A. 1998. Gelidiella womersleyana (Gelidiales, Rhodophyta), a diminute new species from Hawaiian Islands. Bot. Mar. 41(1):51-61.

L'HARDY-HALOS, M.T.H \& MAGSS, C.A. 1991. A novel life history in Aglaothamnion diaphanum sp. nov. (Ceramiaceae, Rhodophyta) from Brittany and the British Isles. Phycologia 30(3):467-479.

L’HARDY-HALOS, M.T. \& RUENESS, J. 1990. Comparative morphology and crossability of related species Aglaothamnion (Rhodophyta). Phycologia 29(3):351-366.

LUCIO, A.M. \& NUNES, J.M.C. 2002. Aportación al conocimiento fenológico de las rodofíceas marinas de la playa de Guarajuba (Camaçari, Bahia) Brasil. Bot. Complut. 26:17-34.

LYRA, G.M., SANTOS, A.C.C. \& NUNES, J.M.C. 2007. Rodofíceas bentônicas das praias da Concha e Engenhoca, Município de Itacaré Bahia, Brasil. Acta Bot. Malacit. 32:234-240.

MAGGS, C.A. \& GUIRY, M.D. 1987. Gelidiella calcicola sp. nov. (Rhodophyta) from the British Isles and Northern France. Brit. Phycol. J. 22(3):417-343.

NORRIS, R.E. 1987. The systematic position of Gelidiopsis and Ceratodictyon (Gigartinales, Rhodophyceae), genera new to South Africa. S. African J. Bot. 53(2):239-246.

NUNES, J.M.C. 1997. Hypneaceae, Rhodymeniaceae, Ceramiaceae e Rhodomelaceae (Rhodophyta) das praias de Placafor e Itapoã, Município de Salvador, Bahia, Brasil. Biotemas 10 (2):61-75.
NUNES, J.M.C. 1998. Rodofíceas marinhas bentônicas da orla oceânica de Salvador, Estado da Bahia, Brasil. Ínsula 27(1):27-37.

NUNES, J.M.C. 2005a. Rodofíceas marinhas bentônicas do estado da Bahia, Bahia. Tese de Doutorado, Universidade de São Paulo, São Paulo, $410 \mathrm{p}$.

NUNES, J.M.C. 2005b. A familia Liagoraceae (Rhodophyta, Nemaliales) no estado da Bahia, Brasil. Hohenea 31(4):429-444.

NUNES, J.M.C. 2007. Duas espécies de Rhodymenia (Rhodophyta, Rhodymeniaceae) no estado da Bahia, Brasil. Acta Bot. Malacit. 32:228-232.

NUNES, J.M.C., GUIMARÃES, S.M.P.B., DONNANGELO, A., FARIAS, J. \& HORTA, P.A. 2008. Aspectos taxonômicos de três espécies de coralináceas não geniculadas do litoral do estado da Bahia, Brasil. Rodriguésia 59(1):75-86.

OLIVEIRA FILHO, E.C. 1969. Algas marinhas do sul do Estado do Espírito Santo (Brasil). I. Ceramiales. Bol. Bot. Univ. São Paulo 343(26):1-277.

OLIVEIRA FILHO, E.C. 1977. Algas Marinhas Bentônicas do Brasil. Tese de Livre-Docência, Universidade de São Paulo, São Paulo.

SANSÓN, M. 1994. Notes on Ceramiaceae (Rhodophyta) from the Canary Islands: New Records and observations on morphology and geografical distribution. Bot. Mar. 37(3):347-356.

SANTELICES, B. 2004. Parviphycus, a new genus in the Gelidiellaceae (Gelidiales, Rhodophyta). Cryptogamie Algol. 25(3):313-326.

SCHNEIDER, C.W. 1983. The red algal genus Audouinella Bory (Nemaliales:Acrochaetiaceae) from North Carolina. Smithsonian Contr. Mar. Sci. 22(1):1-25.

SCHNEIDER, C.W. 1984. Studies on Antithamnionella, Callithamniella and Calloseris (Rhodophyta, Ceramiales) from North Carolina, USA. Phycologia 23(4):455-464.

SCHNEIDER, C.W. \& SEARLES, R.B. 1991. Seaweeds of the southeastern United States: Cape Hatteras to Cape Canaveral. Duke University Press.

SCHNEIDER, C.W. \& SEARLES, R.B. 1997. Notes on the marine algae of the Bermudas. 2. some Rhodophyta. Including Polysiphonia tongatensis and discussion of the Herposiphonia secunda/tenella complex. Cryptog. Algol. (2):187-210.

STEGENGA, H. \& VROMAN, M. 1987. Notes on some Ceramiaceae (Rhodophyta) from Curaçao, especially those from the exposed northeast coast. Blumea 32(3):397-426.

TAYLOR, W.M.R. 1960. Marine Algae of the Eastern Tropical and Subtropical Coasts of the Americas. Michigan Press, Michigan.

WITTMANN, W. 1965. Aceto-iron-haematoxylin-chloral hydrate for chromosome staining. Stain Technology 40(1):161-164.

WOELKERLING, W.J. 1971. Morphology and taxonomy the Audoinella complex (Rhodophyta) in Southern Australia. Austral. J. Bot., Suppl. Ser. 1:1-91

WOMERSLEY, H.B.S. 1998. The marine benthic flora of southern Australia. Rhodophyta - Part IIIC, Ceramiales - Ceramiaceae, Dasyaceae. State Herbarium of South Australia, Adelaide, 535 p.

WYNNE, M.J. 1995. Benthic marine algae from the Seychelles collected during the R/V Te Vega Indian Ocean expedition. Contr. Univ. Michigan Herb. 20(2):261-346.

WYNNE, M.J. 2005. A checklist of the benthic marine algae of the tropical and subtropical western Atlantic: second revision. Beih. Nova Hedwigia 129:1-155.

WYNNE, M.J. \& BALLANTINE, D.L. 1985. Notes on the marine algae of Puerto Rico. IV. The taxonomic placement of Grallatoria (Ceramiaceae, Rhodophyta). Cryptog. Algol. 4(4):219-229.

YONESHIGUE, Y. 1985. Taxonomie et ecologie des algues marines dans la region de Cabo Frio (Rio de Janeiro, Bresil). Tese de Doutorado, Universite D’Aix-Marseille, França. 